\title{
Correlation between Non-Alcoholic Beverage Consumption and Alcohol Drinking Behavior among Japanese Youths
}

\author{
Motoyoshi Kubo' ${ }^{1}$, Yuji Nozu2 ${ }^{2}$, Chie Kataoka², Masako Kudo ${ }^{3}$, Shiori Taniguchi' ${ }^{3}$, \\ Yuki Sato", Naoko Nakayama5, Motoi Watanabe ${ }^{6}$ \\ ${ }^{1}$ Faculty of Education, Utsunomiya University, Utsunomiya, Japan \\ ${ }^{2}$ Faculty of Health and Sport Sciences, University of Tsukuba, Tsukuba, Japan \\ ${ }^{3}$ Graduate School of Comprehensive Human Sciences, University of Tsukuba, Tsukuba, Japan \\ ${ }^{4}$ Narita Junior High School, Tomiya, Japan \\ ${ }^{5}$ St. Luke's International University, Tokyo, Japan \\ ${ }^{6}$ Hokkaido University of Education, Sapporo, Japan \\ Email: kubo@cc.utsunomiya-u.ac.jp
}

Received 1 January 2015; accepted 2 February 2015; published 4 February 2015

Academic Editor: Wayne C. Miller, West Virginia School of Osteopathic Medicine, USA

Copyright (C) 2015 by authors and Scientific Research Publishing Inc.

This work is licensed under the Creative Commons Attribution International License (CC BY). http://creativecommons.org/licenses/by/4.0/

(c) (i) Open Access

\section{Abstract}

The purpose of this study was to investigate the correlation between the consumption of non-alcoholic beverages (such as non-alcoholic beer, non-alcoholic cocktails, and non-alcoholic wine) and alcohol drinking behavior among Japanese youths. Data from the Japan Youth Risk Behavior Survey 2011 were analyzed. The study subjects were 9775 high school students (5026 males and 4749 females) randomly selected from the 10th to the 12th grade in 102 high schools throughout Japan. The results indicated that the percentage of youths who had consumed non-alcoholic beverages was $25.8 \%$ among males (11.5\%: "one time"; $14.3 \%$ : "two or more times") and $26.1 \%$ among females (12.2\%: "one time"; 13.9\%: "two or more times"), which suggested that at least one in four Japanese high school students had consumed non-alcoholic beverages. Those students that had consumed non-alcoholic beverages were at a significantly higher risk for alcohol-related behaviors, including "ever drank alcohol", "current alcohol use", "current frequent alcohol use", and "chugging", when compared with students who had never consumed non-alcoholic beverages. The risk for alcohol-related behaviors was higher for students who had consumed non-alcoholic beverages two or more times than for those who had consumed them one time. Specifically, the odds ratio for "ever drank alcohol" in the "one time" group was 5.16 (95\% CI: 4.22 - 6.30) for males and 4.27 (95\% CI: 3.53 - 5.16) for females, while it was markedly high for those in the "two or more times" group, with males at 9.78 (95\% CI: 7.88 - 12.14) and females at 7.59 (95\% CI: 6.20 - 9.29). 
The results of this study suggest that it is necessary to continuously ascertain the prevalence of non-alcoholic beverage consumption among Japanese youths. In addition, alcohol drinking prevention in youths requires attention be paid not only to their consumption of alcoholic beverages, but also to their consumption of non-alcoholic beverages.

\section{Keywords}

\section{Youth, Non-Alcoholic Beverage, Alcohol Drinking, National Survey}

\section{Introduction}

It is known that when youths drink alcohol, they become more susceptible than adults to a number of health problems such as decreased brain function, liver and other organ dysfunction, and alcohol dependency [1] [2]. In addition, it has been shown that alcohol drinking during youth is a gateway for abuse of drugs, such as marijuana and cocaine [3] [4], and that it is associated with risky traffic-related behaviors, sexual behaviors, cigarettesmoking behaviors, violence, and self-harming behaviors [5]-[7]. Given this, Nozu pointed out that alcohol drinking by youths was the "primary risk behavior". Specifically, alcohol drinking is related to a number of other risk behaviors and occurs prior to these risk behaviors [8]. Furthermore, in studies of Japanese youth, the number of students who start drinking alcohol increases starting in the upper grades of elementary school and that drinking behavior tends to become serious in students who start drinking early [7] [9]. It is clear, therefore, that alcohol drinking of youths is a serious problem and its prevention is one of the most important issues in school health.

A number of large-scale studies investigating trends in alcohol drinking behavior in Japanese youths have reported an improving trend [10]-[12]. However, the situation is still of concern, as $48 \%$ to $53 \%$ of males and $44 \%$ to $54 \%$ of females belong to the "ever drank alcohol" group [10]-[12] and $14 \%$ to $17 \%$ of males and $15 \%$ to $16 \%$ of females belong to the "current alcohol use" group [10] [11]. Thus, alcohol drinking prevention programs for youths must continue to be emphasized and further expanded.

In recent years, non-alcoholic beverages developed as alternatives to alcoholic beverages have become widely available in Japan. These non-alcoholic beverages taste like alcoholic beverages, but have an alcohol content of less than $1 \%$. As these beverages are not considered to be alcoholic beverages under the Liquor Tax Law, they are treated as soft drinks. According to statistics released by the major breweries [13], in 2008, the estimated shipment of non-alcoholic beverages totaled 2.5 million cases ( 1 case $=24$ containers holding $250 \mathrm{ml}$ each). This increased to 28.3 million cases in 2011 and 40.9 million cases in 2013. In addition, over the last several years, beverages with $0.00 \%$ alcohol content have been developed and have quickly become the leading nonalcoholic beverage product sold. Furthermore, a wide variety of non-alcoholic beverages have been developed and are available in the market. For example, in addition to the conventional beer-flavored beverages, cocktailflavored, highball-flavored and plum wine-flavored versions are available now.

The availability of non-alcoholic beverages as alternatives to alcoholic beverages has had a number of effects on people's alcohol consumption-related behaviors, customs and lifestyle [13]. However, when one focuses on the effects these beverages have on youths, it has become clear that it is likely that a serious problem will develop. Specifically, there is a risk that consumption of non-alcoholic beverages by youths and the experience of tastes similar to alcoholic beverages will encourage youths to consume alcoholic beverages. However, the correlation between the consumption of non-alcoholic beverages and alcohol drinking behavior in Japanese youths has not yet been sufficiently investigated.

Thus, this study aimed to clarify the correlation between the consumption of non-alcoholic beverages and alcohol drinking behavior among Japanese youths from a national cross-sectional study.

\section{Methods}

\subsection{Data for Analysis}

The present study used data from the Japan Youth Risk Behavior Survey (JYRBS, 2011) [10], which was a national survey conducted by Nozu et al. from October to December 2011. The subjects were 9778 students in 
the 10th grades through the 12th grade at 102 high schools selected at random from high schools throughout Japan. The subjects used for analysis in the present study were 5026 males and 4749 females, excluding three students who gave invalid answers to the survey question related to non-alcoholic beverage consumption. Demographic characteristics are shown in Table 1. The survey was conducted with the approval of the research ethics committee of the Graduate School of Comprehensive Human Sciences, University of Tsukuba (4 August 2011; No. 23 - 125).

The question related to non-alcoholic beverage consumption was: "Have you consumed one or more glasses of the so-called 'non-alcoholic beverages' that contain less than 1\% alcohol?". The answer selections were "no", "one time", and "two or more times". The categories for alcohol drinking behavior were: "ever drank alcohol", "current alcohol use" (drank on at least one day 30 days before the survey), "current frequent alcohol use" (drank on at least 10 days 30 days before the survey), and "chugging".

\subsection{Analytical Methods}

The percentages of subjects who have consumed non-alcoholic beverages were calculated according to gender and grade. The gender and grade differences were investigated using the chi-square test.

The correlation between non-alcoholic beverage consumption and alcohol drinking behavior was investigated first by dividing the subjects into three groups according to the consumption experience of non-alcoholic beverages ("no", "one time", and "two or more times"), calculating the percentages of subjects in each alcohol drinking behavior category according to gender and grade, and then applying the chi-square test. Next, we used non-alcoholic beverage consumption as the independent variable and the alcohol drinking behavior categories as the dependent variables, and applied multiple logistic regression analysis that was adjusted for the influence of grade to each gender. Specifically, we calculated the odds ratio and $95 \%$ confidence interval of two of the groups ("one time" group and "two or more times" group), with the "no" group set as " 1 ".

Statistical significance was set at 5\%. The statistical package used was IBM SPSS Statistics 20.

\section{Results}

\subsection{Prevalence of Non-Alcoholic Beverage Consumption}

The percentage of subjects who had consumed non-alcoholic beverages across all three grades was $25.8 \%$ for males ("one time" was $11.5 \%$ and "two or more times" was $14.3 \%$ ) and $26.1 \%$ for females ("one time" was $12.2 \%$ and "two or more times" was $13.9 \%$ ). No significant difference was observed between males and females (Table 2).

As evaluated according to grade, non-alcoholic beverage consumption was $24.8 \%$ to $27.9 \%$ for males ("one time" was $11.2 \%$ to $12.1 \%$ and "two or more times" was $12.7 \%$ to $16.7 \%$ ). Although no significant differences were observed between the grades, 12th grade students had the highest percentage. There were significant differences between the grades for those in the "two or more times" group. For females, the figure was $23.8 \%$ to $27.8 \%$ ("one time" was $11.3 \%$ to $13.0 \%$ and "two or more times" was $12.5 \%$ to $15.4 \%$ ). Significant differences were observed between grades, with a trend toward higher percentages in the higher grades. No significant differences were observed between the genders for any grade.

\subsection{Percentages of Alcohol Drinking Behavior by Non-Alcoholic Beverage Consumption}

Looking at the percentages of subjects in all grades as a whole, significant differences were observed between the three groups of those who had consumed non-alcoholic beverages for the four categories of alcohol drinking behavior (ever drank alcohol, current alcohol use, current frequent alcohol use, and chugging; Table 3). The percentages for subjects in the "ever drank alcohol" group were as follows: $36.5 \%$ of males and $33.1 \%$ of females who answered "no" to non-alcoholic beverage consumption, $74.3 \%$ for males and $67.9 \%$ for females in the "one time" group, and $84.7 \%$ for males and $78.6 \%$ for females in the "two or more times" group. For both males and females, the percentages were higher when the subjects reported that they drank non-alcoholic beverages more times. The same trend was seen in the percentages for "current alcohol use", "current frequent alcohol use", and "chugging".

When evaluated at according to grade, significant differences were observed between the three non-alcoholic beverage consumption groups in all grades for "ever drank alcohol", "current alcohol use", and "chugging", and 
Table 1. Demographic characteristics.

\begin{tabular}{cccccc}
\hline & & 10 th & 11 th & 12 th & Total \\
\hline Males & $\mathrm{n}(\%)$ & $1785(35.5)$ & $1673(33.3)$ & $1568(31.2)$ & $5026(100)$ \\
Females & $\mathrm{n}(\%)$ & $1659(34.9)$ & $1643(34.6)$ & $1447(30.5)$ & $4749(100)$ \\
\hline
\end{tabular}

There were no significant differences between males and females (chi-square test, $\mathrm{df}=2$ ).

Table 2. Prevalence of non-alcoholic beverage consumption.

\begin{tabular}{|c|c|c|c|c|c|c|c|}
\hline & & \multicolumn{2}{|c|}{ Non-alcoholic beverage consumption } & \multicolumn{2}{|c|}{ "One time" } & \multicolumn{2}{|c|}{ "Two or more times" } \\
\hline & & $\%$ & Grade difference $^{\dagger}$ & $\%$ & Grade difference $^{\dagger}$ & $\%$ & Grade difference $^{\dagger}$ \\
\hline \multirow[t]{4}{*}{ Males } & 10th & 25.0 & & 11.3 & & 13.7 & \\
\hline & 11 th & 24.8 & n.s. & 12.1 & n.s. & 12.7 & $\mathrm{p}<0.05$ \\
\hline & 12 th & 27.9 & & 11.2 & & 16.7 & \\
\hline & Total & 25.8 & - & 11.5 & - & 14.3 & - \\
\hline \multirow[t]{4}{*}{ Females } & 10 th & 23.8 & & 11.3 & & 12.5 & \\
\hline & 11 th & 26.9 & $\mathrm{p}<0.05$ & 13.0 & n.s. & 13.9 & n.s. \\
\hline & 12 th & 27.8 & & 12.4 & & 15.4 & \\
\hline & Total & 26.1 & - & 12.2 & - & 13.9 & - \\
\hline
\end{tabular}

There were no significant differences between males and females in all categories (chi-square test, $\mathrm{df}=1$ ). ${ }^{\dagger} \mathrm{Chi}$-square tests were carried out by gender $(\mathrm{df}=2)$; n.s.: not significant.

Table 3. Percentages of alcohol drinking behavior by non-alcoholic beverage consumption.

\begin{tabular}{|c|c|c|c|c|c|c|c|c|}
\hline & \multicolumn{4}{|c|}{ Males } & \multicolumn{4}{|c|}{ Females } \\
\hline & \multicolumn{3}{|c|}{ Non-alcoholic beverage consumption } & \multicolumn{5}{|c|}{ Non-alcoholic beverage consumption } \\
\hline & "No" & "One time" & $\begin{array}{l}\text { "Two or more } \\
\text { times" }\end{array}$ & \multirow{2}{*}{$\chi^{2}$} & "No" & "One time" & $\begin{array}{c}\text { "Two or } \\
\text { more times" }\end{array}$ & \multirow{2}{*}{$\chi^{2}$} \\
\hline & $\%$ & $\%$ & $\%$ & & $\%$ & $\%$ & $\%$ & \\
\hline \multicolumn{9}{|c|}{ Ever drank alcohol } \\
\hline 10 th & 30.0 & 71.8 & 81.6 & $307.71^{*}$ & 26.1 & 65.2 & 75.0 & $257.26^{*}$ \\
\hline 11 th & 36.2 & 73.4 & 86.8 & $248.91^{*}$ & 34.3 & 69.6 & 78.1 & $207.43^{*}$ \\
\hline 12 th & 44.6 & 78.2 & 85.9 & $187.81^{*}$ & 40.0 & 68.5 & 82.4 & $158.78^{*}$ \\
\hline Total & 36.5 & 74.3 & 84.7 & $740.34^{*}$ & 33.1 & 67.9 & 78.6 & $621.83^{*}$ \\
\hline \multicolumn{9}{|c|}{ Current alcohol use } \\
\hline 10th & 8.0 & 20.3 & 34.8 & $140.03^{*}$ & 7.4 & 23.0 & 38.9 & $172.77^{*}$ \\
\hline 11 th & 9.6 & 19.7 & 40.6 & $140.98^{*}$ & 10.5 & 26.2 & 36.0 & $110.02^{*}$ \\
\hline 12 th & 15.8 & 30.9 & 46.6 & $121.51^{*}$ & 13.5 & 23.5 & 46.8 & $129.32^{*}$ \\
\hline Total & 10.9 & 23.3 & 40.8 & $405.36^{*}$ & 10.3 & 24.3 & 40.6 & $405.05^{*}$ \\
\hline \multicolumn{9}{|c|}{ Current frequent alcohol use } \\
\hline 10 th & 0.6 & 1.5 & 5.7 & $38.60^{*}$ & 0.6 & 1.1 & 1.9 & 3.56 \\
\hline 11 th & 1.0 & 0.5 & 5.2 & $23.74^{*}$ & 0.3 & 1.4 & 3.5 & $24.54^{*}$ \\
\hline 12 th & 2.0 & 3.4 & 4.2 & 4.86 & 0.8 & 0.6 & 1.4 & 0.91 \\
\hline Total & 1.2 & 1.7 & 5.0 & $51.17^{*}$ & 0.6 & 1.0 & 2.3 & $19.80^{*}$ \\
\hline \multicolumn{9}{|l|}{ Chugging } \\
\hline 10 th & 3.6 & 8.9 & 16.3 & $62.30^{*}$ & 3.0 & 7.5 & 10.6 & $28.77^{*}$ \\
\hline 11 th & 4.1 & 13.8 & 16.5 & $60.96^{*}$ & 4.6 & 9.3 & 11.0 & $18.33^{*}$ \\
\hline 12 th & 8.5 & 16.0 & 28.1 & $74.65^{*}$ & 4.8 & 12.3 & 22.9 & $80.55^{*}$ \\
\hline Total & 5.3 & 12.8 & 20.6 & $200.89^{*}$ & 4.1 & 9.7 & 14.9 & $123.37^{*}$ \\
\hline
\end{tabular}

$\mathrm{df}=2$ for each $\chi^{2} ;{ }^{*} \mathrm{p}<0.05$. 
significant differences between males in the 10th and 11th grades and females in the 11th grade for "current frequent alcohol use." In general, these differences showed the same trend toward higher percentages in groups that reported more frequent non-alcoholic beverage consumption as seen in the percentages for all subjects regardless of grade.

\subsection{Odds Ratios for Alcohol Drinking Behavior According to Those Who Have Consumed Non-Alcoholic Beverages versus Those Who Have Not Consumed Non-Alcoholic Beverages}

The odds ratios and $95 \%$ confidence intervals calculated using multiple logistic regression analysis are shown in Table 4. In the group of subjects that reported consuming non-alcoholic beverages "one time", significant odds ratios were observed for "ever drank alcohol" (odds ratios = males: 5.16; females: 4.27), "current alcohol use" (males: 2.50; females: 2.79), and "chugging" (males: 2.65; females: 2.51). In the group of subjects that reported consuming non-alcoholic beverages "two or more times", significant odds ratios were observed in all drinking behavior categories for "ever drank alcohol" (males: 9.78; females: 7.59), "current alcohol use" (males: 5.57; females: 5.91), "current frequent alcohol use" (males: 4.39; females: 4.22), and "chugging" (males: 4.56; females: 4.05). In both males and females in all four alcohol drinking behavior categories, those who reported consuming non-alcoholic beverage "two or more times" had higher odds ratios than those who reported "one time". Among the alcohol drinking behavior, both males and females had higher odds ratios for "ever drank alcohol" than any of the other three behaviors.

\section{Discussion}

In the present study, the prevalence of non-alcoholic beverage consumption among Japanese high school students was $25.8 \%$ of males and $26.1 \%$ of females which indicates that at least one in four high school students had consumed non-alcoholic beverages. When evaluated at according to grade, percentages are higher for both males and females in higher grades, with 12 th grade males at $27.9 \%$ and 12 th grade females at $27.8 \%$. Of those who reported consuming non-alcoholic beverages, both males and females in the "two or more times" group comprised at least half of all subjects who had consumed non-alcoholic beverages, indicating repeated consumption. On the other hand, the percentage of Japanese high school students who reported consuming non-alcoholic beverages was approximately half the recently-reported percentage of high school students who had ever drunk alcohol (males: $48 \%$ to $53 \%$; females: $44 \%$ to $54 \%$ ) [10]-[12].

The national survey conducted by Ohida et al. (2012) also indicated that $27.8 \%$ of male high school students and $35.3 \%$ of female high school students have consumed non-alcoholic beverages [11]. Although the subject extraction methods and implementation methods of the two surveys differ, both surveys indicate considerable prevalence of non-alcoholic beverage consumption among Japanese high school students. Continued study of this trend and associated issues is necessary.

Table 4. Odds ratios for alcohol drinking behavior according to those who have consumed non-alcoholic beverages versus those who have not consumed non-alcoholic beverages.

\begin{tabular}{|c|c|c|c|c|c|c|c|}
\hline & & \multicolumn{3}{|c|}{ Males } & \multicolumn{3}{|c|}{ Females } \\
\hline & & \multicolumn{3}{|c|}{ Non-alcoholic beverage consumption } & \multicolumn{3}{|c|}{ Non-alcoholic beverage consumption } \\
\hline & & "No" & "One time" & $\begin{array}{c}\text { "Two or } \\
\text { more times" }\end{array}$ & "No" & "One time" & $\begin{array}{c}\text { "Two or } \\
\text { more times" }\end{array}$ \\
\hline \multirow[t]{2}{*}{ Ever drank alcohol } & $\mathrm{AOR}^{\dagger}$ & 1.00 & $5.16^{*}$ & $9.78^{*}$ & 1.00 & $4.27^{*}$ & $7.59^{*}$ \\
\hline & $95 \% \mathrm{CI}^{\S}$ & Reference & $4.22-6.30$ & $7.88-12.14$ & Reference & $3.53-5.16$ & $6.20-9.29$ \\
\hline \multirow[t]{2}{*}{ Current alcohol use } & $\mathrm{AOR}^{\dagger}$ & 1.00 & $2.50^{*}$ & $5.57^{*}$ & 1.00 & $2.79^{*}$ & $5.91^{*}$ \\
\hline & $95 \% \mathrm{CI}^{\S}$ & Reference & $2.00-3.11$ & $4.64-6.70$ & Reference & $2.24-3.47$ & $4.88-7.16$ \\
\hline Current frequent & $\mathrm{AOR}^{\dagger}$ & 1.00 & 1.51 & $4.39^{*}$ & 1.00 & 1.89 & $4.22^{*}$ \\
\hline alcohol use & $95 \% \mathrm{CI}^{\S}$ & Reference & $0.75-3.02$ & $2.79-6.92$ & Reference & $0.75-4.75$ & $2.13-8.35$ \\
\hline \multirow[t]{2}{*}{ Chugging } & $\mathrm{AOR}^{\dagger}$ & 1.00 & $2.65^{*}$ & $4.56^{*}$ & 1.00 & $2.51^{*}$ & $4.05^{*}$ \\
\hline & $95 \% \mathrm{CI}^{\S}$ & Reference & $1.99-3.53$ & $3.61-5.76$ & Reference & $1.81-3.46$ & $3.08-5.33$ \\
\hline
\end{tabular}

${ }^{\dagger}$ Adjusted odds ratio for grade (10th, 11 th and 12 th); ${ }^{\S} 95 \%$ confidence interval; ${ }^{*} \mathrm{p}<0.05$. 
Next, we investigated the correlation between consumption of non-alcoholic beverages and alcohol drinking behavior of high school students. Although the risk that consumption of non-alcoholic beverages may encourage the alcohol drinking by youths has been pointed out previously, a correlation between the two behaviors had not been investigated. The present study found that markedly higher percentages of both males and females who had consumed non-alcoholic beverages responded positively to "ever drank alcohol", "current alcohol use", "current frequent alcohol use", and "chugging". Of these, those who reported consuming non-alcoholic beverages "two or more times" had higher percentages than those who reported consuming non-alcoholic beverages "one time". Moreover, the risk of being in the "ever drank alcohol" group was 5.16 times higher for males and 4.27 times higher for females in the group that reported consuming non-alcoholic beverages "one time" than those in the "no" group. This figure was 9.78 times higher for males and 7.59 times higher for females in the group that reported consuming non-alcoholic beverages "two or more times".

As the results of this study were based on a cross-sectional study, they do not establish a causal relationship between the consumption of non-alcoholic beverages and the alcohol drinking behavior of high school students. This is a limitation of this study. Realistically, it can only be said that it is possible that youths who consume non-alcoholic beverages virtually experience a taste that is similar to alcoholic beverages and the environment of drinking alcohol, and that this can be linked to lowered psychological resistance to consuming alcoholic beverages and increased interest in consuming alcoholic beverages, which may lead to the actual consumption of alcoholic beverages. However, it is also possible that youths who have drunk alcoholic beverages consume nonalcoholic beverages as an alternative to alcoholic beverages. Even so, the results of the present study, which are based on a cross-sectional study, clearly indicate that a markedly higher percentage of youths who have consumed non-alcoholic beverages reported having "ever drank alcohol" than those who had not consumed nonalcoholic beverages. This is an important finding. Thus, programs designed to prevent youths from drinking alcohol should also pay attention to the consumption of non-alcoholic beverages.

Finally, we will consider actions being taken regarding non-alcoholic beverages to prevent the consumption of alcoholic beverages by youths. In Japan, beverage manufacturers and vendors have established self-imposed standards that are strictly followed just as with alcoholic beverages. These standards include the advertisement and sale of non-alcoholic beverages not using phrasing that endorses drinking by minors, labels clearly stating that products are intended for consumers aged 20 and over, carefully considering the display locations of such products, and age verification at the time of each sale [14] [15]. These measures are a significant step toward the prevention of alcohol drinking by youths, and it would best that they are continuously carried out and expanded over time. We would also recommend that the guidance and measures regarding non-alcoholic beverage consumption provided in homes and schools be improved. According to a survey of parents and guardians with minor children, approximately $64 \%$ of the parents and guardians have a tolerant attitude toward the consumption of non-alcoholic beverages by minors [16]. It is important that measures in homes and schools are designed to prevent the consumption of alcoholic beverages by youths, and it must be made clear that the consumption of both alcoholic and non-alcoholic beverages is not condoned. Further appropriate guidelines and measures must be developed to address these issues.

\section{Conclusions}

This study used data from a national survey from the 10th to the 12th grade students (5026 males; 4749 females) at high schools throughout Japan that were randomly selected to elucidate the correlation between non-alcoholic beverage consumption and alcohol drinking behavior. The results showed that $25.8 \%$ of males and $26.1 \%$ of females had consumed non-alcoholic beverages, indicating that at least one in four Japanese high school students had consumed non-alcoholic beverages. It was also made clear that in comparison with those who had not consumed non-alcoholic beverages those who had consumed non-alcoholic beverages had higher percentages of "ever drank alcohol", "current alcohol use", "current frequent alcohol use" and "chugging". Moreover, those who reported consuming non-alcoholic beverages "two or more times" were at higher risk of alcohol drinking behavior than those who reported drinking non-alcoholic beverages "one time".

The results of this study indicate that further continuous studies of the prevalence of non-alcoholic beverage consumption by Japanese youths are necessary, and suggest that programs designed to prevent alcohol drinking by youths must pay attention not only to alcoholic beverage consumption but also to non-alcoholic beverage consumption. 


\section{Acknowledgements}

The authors would like to thank the school staff members and students who cooperated in this study. This work was supported by JSPS KAKENHI (22500622).

\section{References}

[1] National Institute on Alcohol Abuse and Alcoholism (2006) Underage Drinking. Alcohol Alert, 67, 1-7. http://pubs.niaaa.nih.gov/publications/AA67/AA67.pdf

[2] U.S. Department of Health and Human Services (2007) The Surgeon General's Call to Action to Prevent and Reduce Underage Drinking. Office of the Surgeon General, Rockville.

[3] Kandel, D. (1975) Stages in Adolescent Involvement in Drug Use. Science, 190, 912-914. http://dx.doi.org/10.1126/science.1188374

[4] Ellickson, P.L., Hays, R.D. and Bell, R.M. (1992) Stepping through the Drug Use Sequence: Longitudinal Scalogram Analysis of Initiation and Regular Use. Journal of Abnormal Psychology, 101, 441-451. http://dx.doi.org/10.1037/0021-843X.101.3.441

[5] Stueve, A. and O’Donnell, L.N. (2005) Early Alcohol Initiation and Subsequent Sexual and Alcohol Risk Behaviors among Urban Youths. American Journal of Public Health, 95, 887-893. http://dx.doi.org/10.2105/AJPH.2003.026567

[6] Nozu, Y., Watanabe, Ma., Watanabe, Mo., Shimomura, Y., Ichimura, K., Arakawa, O., et al. (2006) Youth Risk Behavior among Japanese High School Students: Results of the 2001 National Survey. Japanese Journal of School Health, 48, 430-447. (In Japanese, Abstract in English)

[7] Kubo, M., Nozu, Y., Sato Y., Uehara, C. and Watanabe, M. (2008) Relationships between Early Experience of Smoking and Drinking, and Engaging in Multiple Risk Behaviors in Subsequent High School Years among Japanese Adolescents. Japanese Journal of School Health, 50, 123-136. (In Japanese, Abstract in English)

[8] Nozu, Y. (2006) Program Development for Preventing Alcohol Use among Japanese Youth. Japanese Journal of School Health, 47, 491-500. (In Japanese)

[9] Takakura, M. and Wake, N. (2003) Association of Age at Onset of Cigarette and Alcohol Use with Subsequent Smoking and Drinking Patterns among Japanese High School Students. Journal of School Health, 73, 226-231. http://dx.doi.org/10.1111/j.1746-1561.2003.tb06566.x

[10] Nozu, Y. (2013) National Survey on Youth Risk Behaviors and Resilience in Japan. (In Japanese) https://kaken.nii.ac.jp/pdf/2012/seika/C-19 1/12102/22500622seika.pdf

[11] Ohida, T., Suzuki, K., Higuchi, S., Kaneita, Y., Kanda, H., Osaki, Y., et al. (2013) A Survey Research on Underage Smoking, Drinking Situation. (In Japanese) http://www.med.nihon-u.ac.jp/department/public health/2012 CK KI2.pdf

[12] Yoshimoto, S., Kito, H., Nishioka, N., Ezaki, K., Nagai, J. and Wada, K. (2012) A Fixed Point Follow-Up Survey about Drug Abuse and These Background Factor in High School Student (1) Study Design and Prevalence of Drug Abuse. Japanese Journal of School Health, 54 Suppl., S252. (In Japanese)

[13] Suntory Holdings Limited (2014) A Survey of the Drinking Situation of Consumers about Non-Alcoholic Beverages: Suntory Non-Alcoholic Beverages Report 2014. (In Japanese) http://www.suntory.co.jp/news/2014/12092.html

[14] Liaison Committee about Alcohol Drinking (2012) Self-Standard about the Indication of the Advertisement of Alcoholic Beverages and the Alcoholic Beverages Container, 5-6. (In Japanese) http://www.rcaa.jp/standard/pdf/jishukijun.pdf

[15] National Research Institute of Brewing, Japan (2014) A Model Text for the Training of the Alcoholic Beverages Sales Management, 26-48. (In Japanese) http://www.nrib.go.jp/kou/pdf/nrib_model14030.pdf

[16] Miyaki, Y. (2012) Pros and Cons: Consumption of Non-Alcoholic Beverages. Life Design Report, 204, 38-40. (In Japanese) http://group.dai-ichi-life.co.jp/dlri/ldi/watching/wt1208.pdf 
Scientific Research Publishing (SCIRP) is one of the largest Open Access journal publishers. It is currently publishing more than 200 open access, online, peer-reviewed journals covering a wide range of academic disciplines. SCIRP serves the worldwide academic communities and contributes to the progress and application of science with its publication.

Other selected journals from SCIRP are listed as below. Submit your manuscript to us via either submit@scirp.org or Online Submission Portal.
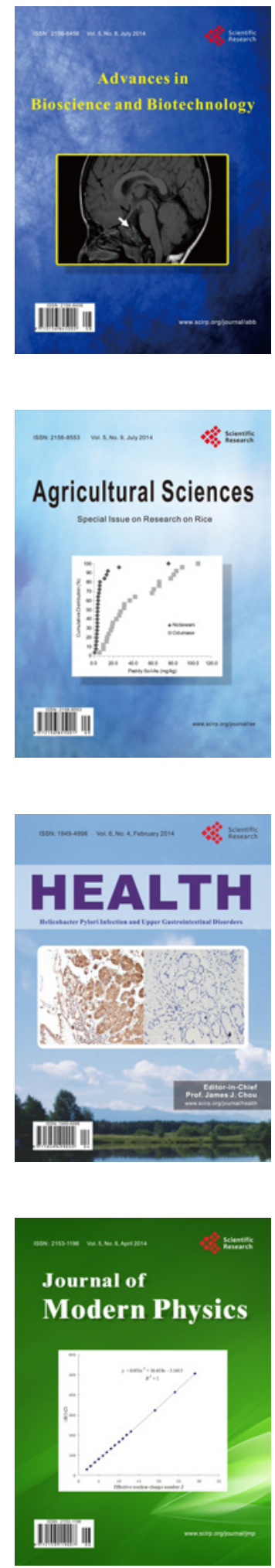
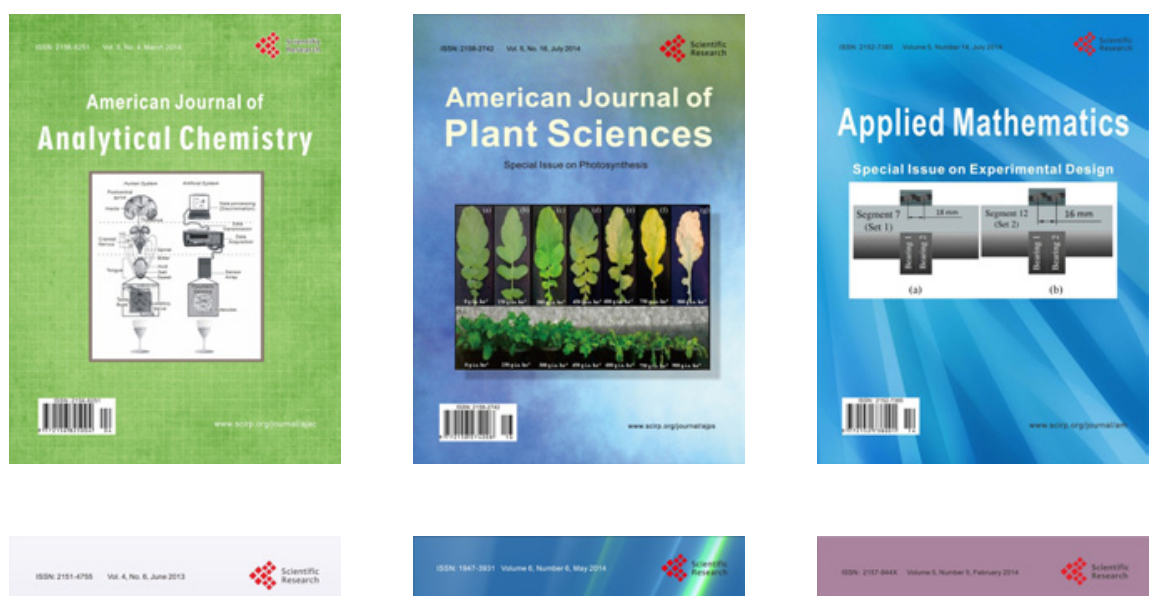

Creative Education
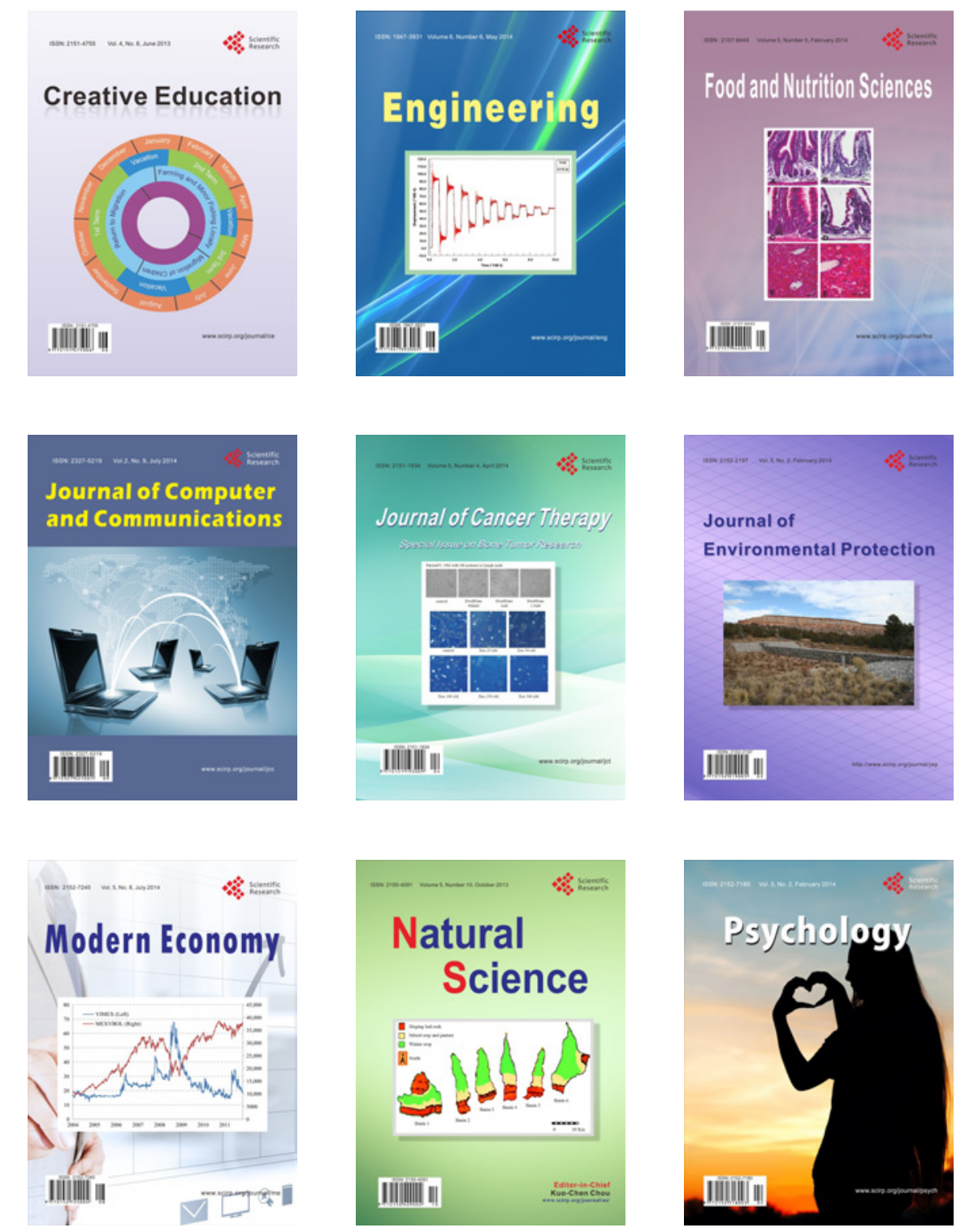